\title{
Effectiveness of ambulance paramedics versus ambulance technicians in managing out of hospital cardiac arrest
}

\author{
Jonathan S Nguyen-Van-Tam, Andrew F Dove, Martin P Bradley, James C G Pearson, \\ Patrick Durston, Richard J Madeley
}

University of Nottingham Medical School, Queens Medical Centre, Nottingham NG7 2UH: Department of Public Health Medicine and Epidemiology J S Nguyen-Van-Tam M P Bradley J C G Pearson R J Madeley

Department of Accident and Emergency A F Dove

Nottinghamshire Ambulance Service NHS Trust, Ambulance Headquarters, Beechdale Road, Nottingham NG8 3LL P Durston

Correspondence to: Dr J Van-Tam.

Accepted for publication 20 February 1997

\begin{abstract}
Objective-To determine the effectiveness of extended trained ambulance personnel (paramedics) for the management of out of hospital cardiac arrest.

Methods-A retrospective cohort study of patients who suffered a cardiac arrest between 1 January 1992 and 31 July 1994, and who were transported to their local accident and emergency (A\&E) department. Data were collected on basic demography, operational time intervals, and ambulance crew status. Further clinical data were collected, and outcome measures included status on arrival at $A \& E$, status on leaving A\&E (hospital admission), and status on leaving hospital. The data were analysed using univariate and multivariate techniques.
\end{abstract}

Results-Univariate analysis showed the likelihood of arriving in $A \& E$ with a return of spontaneous circulation was more than doubled among patients attended by a paramedic crew compared with those attended by technicians (relative risk $=2.48,95 \%$ confidence interval 1.34 to 4.60). The likelihood of successful hospital admission was also significantly increased ( $R R=1.92,95 \%$ CI 1.13 to 3.27$)$; however, beyond this point, further survival benefits appeared to be much smaller. Similar findings were revealed using multivariate analysis. Second level modelling revealed further possible differences between paramedic and technician crews according to type of incident. Patients successfully admitted to hospital who died before discharge remained severely disabled between admission and death.

Conclusions-There are marked short term survival advantages after cardiac arrest associated with paramedic care, but these probably diminish rapidly over time.

(F Accid Emerg Med 1997;14:142-148)

Keywords: cardiac arrest; paramedics; ambulance technicians; outcome

In the United Kingdom, authorisation for extended training of ambulance personnel was given in $1984^{1}$; however, it was not until 1990 that the Secretary of State for Health instructed that by 1996 there should be at least one extended trained crew member (paramedic) on every emergency ambulance. ${ }^{2}$

In Nottinghamshire, basic life support (BLS) and defibrillation are practised by all emergency ambulance crews. The use of early defibrillatory shock for patients in ventricular fibrillation has been widely studied and shown to improve survival to hospital discharge dramatically. ${ }^{3-6}$ Most studies of bystander cardiopulmonary resuscitation (CPR) suggest that this technique is also effective in improving survival. ${ }^{7}$ Paramedic ambulance personnel are trained to perform additional resuscitative procedures such as tracheal intubation, intravenous cannulation, and drug/fluid administration $^{8}$; however, few British studies have examined the effectiveness of paramedics compared to technicians and the data are not yet conclusive. A study performed recently in Edinburgh failed to show any added value of paramedics over ambulance technicians capable of performing semi-automatic defibrillation for the management of out of hospital cardiac arrest. ${ }^{9}$ Similar data have also been produced by researchers in Hampshire. ${ }^{10}$

In Nottingham, the phased introduction of paramedic crews, which began in 1987, has provided an opportunity to study out of hospital cardiac arrests to determine how the deployment of paramedic ambulance personnel has affected patient outcomes.

\section{Methods}

Nottingham is served by a single accident and emergency (A\&E) department located at one of its two major teaching hospitals. This department handles in excess of 125000 new cases per annum from a largely urbanised catchment population of 800000 which extends slightly beyond the boundaries of Nottingham Health District.

The Nottinghamshire Ambulance Service operates a policy of despatching to any emergency call the nearest available vehicle regardless of crew status. During the study period, upon arrival at the scene of a cardiac arrest the attending crew were called upon to decide whether or not to begin resuscitation on the basis of clinical signs, the presence of ongoing bystander CPR, and the available history; this remains current practice. Additionally, an informal practice arose whereby crews composed of technicians sometimes requested paramedic assistance (dual response); however, in 1993 this was officially stopped 
because it had become apparent that long delays on scene resulted, and the attendance of two crews at one incident sometimes reduced the availability of vehicles for other tasks. In cases where patients obviously died several hours ago, crews call the patient's general practitioner to certify death. All other patients are transported to the $\mathrm{A} \& \mathrm{E}$ department. When resuscitation is started it is always continued until arrival at the $A \& E$ department. Certain patients are certified dead in the emergency vehicle by $A \& E$ medical staff, according to the length and success of resuscitative efforts to date; these patients are classified as "brought in dead". The remainder enter the department for continued resuscitation. Almost all ongoing out of hospital cardiac arrests are transported to the $\mathrm{A} \& \mathrm{E}$ department, although a very small number of general practitioner (GP) referred patients who arrest during transit from their homes to the coronary care unit (CCU) of Nottingham's other main hospital continue their original journey if, at the time of the arrest, this is obviously very much closer.

We performed a retrospective cohort study of out of hospital cardiac arrests attended by a Nottinghamshire ambulance crew and transported to the A\&E department between 1 January 1992 and 31 July 1994. Patients aged 15 years and over suffering cardiac arrest were identified from $A \& E$ computerised records and the admissions registers of the intensive therapy unit (ITU), high dependency unit (HDU), and CCU in the same hospital. All aetiologies were included. Patients brought in dead, declared dead on arrival, or who died in the A\&E department were included, as were patients who arrested during transit. Hospital necropsy registers were also cross referenced to increase the chances of complete ascertainment. Interhospital transfers and incidents which involved the $A \& E$ flying squad were excluded. Details of prehospital care were obtained from ambulance patient report forms stored in $A \& E$ patient folders, or copies held at one of the 12 ambulance stations in Nottinghamshire. The data collected included basic demography, operational time intervals, and crew status (either solely technicians, or at least one paramedic). Dual response calls were also described but excluded from all statistical analyses. Further data were collected largely in conformity with the recommendations of the European Resuscitation Council and the American Heart Association (Utstein guidelines), and a system proposed by Eisenberg $e t$ $a .^{11}{ }^{12}$ These included aetiology (classified into cardiac (presumed) $v$ non-cardiac causes), initial cardiac arrhythmia (classified into ventricular fibrillation $v$ ventricular tachycardia $v$ other), bystander CPR, defibrillatory shock, paramedic procedures performed (including intubation, intravenous access, and drugs given), and the presence of a medical practitioner at the scene of the arrest. Multiple outcomes were considered: status on arrival at $\mathrm{A} \& \mathrm{E}$ (return of spontaneous circulation, declared dead, or still undergoing CPR); status on leaving A\&E (admitted to hospital unit); and status on leaving hospital (discharged alive), including length of stay. It was not possible within the scope of this study to determine one year survival. GlasgowPittsburgh scales were used to describe optimal cerebral and overall function between admission and discharge, or between admission and death. ${ }^{1314}$

The study was conducted in accordance with ethical guidelines issued by the Royal College of Physicians of London for studies involving personal medical records. ${ }^{15}$

\section{STATISTICAL ANALYSES}

Univariate analyses were performed using $\chi^{2}$ tests with Yates correction (EPI-INFO), Kruskal-Wallis, and Mann-Whitney tests (SPSS-PC). Multivariate analyses were performed using Poisson regression (EGRET). The modelling strategy employed began with a saturated model including variables for age (quartile groups), sex, crew status (technician or paramedic), initial cardiac arrhythmia (ventricular $v$ other), aetiology of arrest (cardiac $v$ non-cardiac), witnessed arrest, bystander CPR, response time (call receipt to vehicle stops) ${ }^{11}$ and transfer time (departure from scene to arrival at EM department) ${ }^{11}$ in quartile bands, and the presence of a medical practitioner at the scene of the arrest. While retaining crew status in the model, other variables with the smallest effect on outcome were then removed one by one until those that remained all made a significant contribution to the model. Several interactions were of potential importance in determining if paramedic crews performed differently according to the presence of ventricular $v$ other arrhythmia, cardiac $v$ non-cardiac aetiology, and witnessed $v$ unwitnessed arrest. These were explored by adding product terms to each model; those which significantly altered the model are described in the results. A separate model was constructed for each of the three stages in outcome. In addition three separate alternative models (based on smaller numbers because of missing data) were constructed to adjust for any potential effect on outcome brought about by our inclusion of patients who may have arrested after the arrival of the ambulance crew.

Based on an estimated 700 patients, the study size provided a power in excess of $90 \%$ to detect a difference of $10 \% \quad v 20 \%$ survival (relative risk $=2.0$ ) at $\mathrm{P}<0.05$, assuming a paramedic:technician ratio of $2: 1$; however, based on the 429 patients actually analysed, the study size provided a power in excess of $75 \%$ to detect this difference.

\section{Results}

During the study period, 734 patients who fulfilled the study criteria were transported to the $A \& E$ department, and ambulance patient reports were successfully retrieved for 508 $(69.2 \%)$. Of the 226 missing ambulance reports, $215(95.1 \%)$ related to patients known to have been brought in dead or declared dead on arrival.

Table 1 describes the main demographic characteristics and prehospital details of 
Table 1 Demographic and prehospital details for 508 patients with out of hospital cardiorespiratory arrest according to ambulance crew status

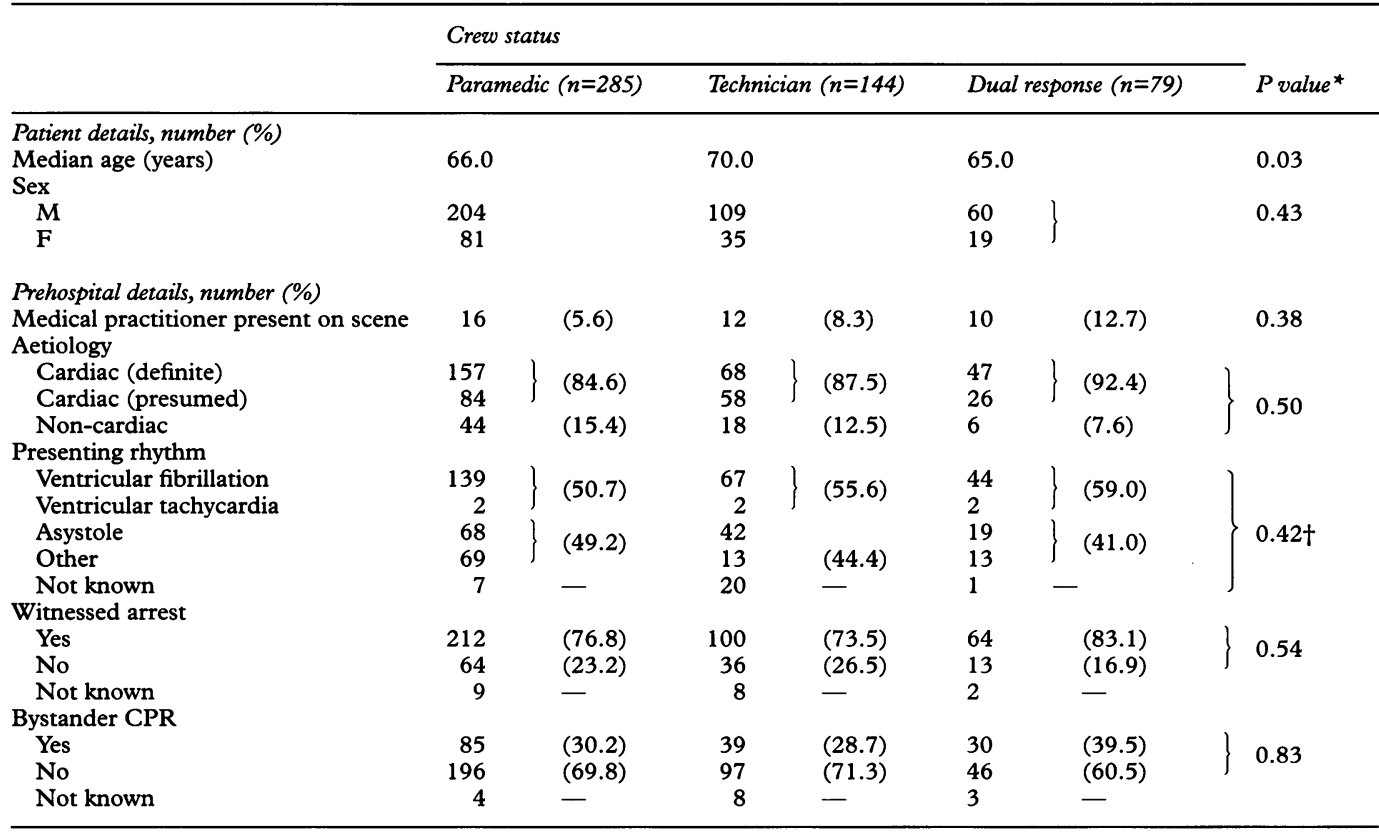

$\star$ Paramedic versus technician (dual response excluded).

† Ventricular versus other rhythm.

Table 2 Median operational time intervals (minutes) and procedures performed during out of hospital cardiorespiratory arrest according to ambulance crew status

\begin{tabular}{|c|c|c|c|c|c|c|c|}
\hline & \multicolumn{6}{|c|}{ Crew status } & \multirow[b]{2}{*}{$P$ value } \\
\hline & \multicolumn{2}{|c|}{ Paramedic $(n=285)$} & \multicolumn{2}{|c|}{ Technician ( $n=144)$} & \multicolumn{2}{|c|}{ Dual response $(n=79)$} & \\
\hline \multicolumn{8}{|c|}{ Time intervals, median (min) } \\
\hline Response† & 5.0 & & 6.0 & & 6.0 & & \\
\hline On scenet & 31.0 & & 17.5 & & 39.0 & & $<0.001$ \\
\hline Transfert & 8.0 & & 9.0 & & 7.0 & & \\
\hline \multirow{2}{*}{\multicolumn{8}{|c|}{$\begin{array}{l}\text { Procedures, number (\%) } \\
\text { Defibrillatory shock }\end{array}$}} \\
\hline Defibrillatory shock & & & & & & & \\
\hline Yes & 170 & (59.6) & 76 & $(54.3)$ & 52 & (67.5) & 0.34 \\
\hline No & 115 & $(40.4)$ & 64 & $(45.7)$ & 25 & (32.5) & \\
\hline Not known & 0 & - & 4 & - & 2 & - & \\
\hline \multicolumn{8}{|c|}{ Extended role paramedic procedure } \\
\hline Yes & 257 & (91.5) & - & - & 73 & $(96.0)$ & NA \\
\hline No & 24 & $(8.5)$ & - & - & 3 & $(4.0)$ & \\
\hline Not known & 4 & - & - & - & 3 & - & \\
\hline
\end{tabular}

$\star$ Paramedic versus technician (dual response excluded).

+ See main text for definition.

patients according to crew status. In general, patients treated by paramedics were younger than those treated by technicians, but no other significant differences were noted between the two groups with respect to gender, aetiology, ventricular $v$ non-ventricular presenting rhythm, witnessed arrests, bystander CPR, and the presence of a medical practitioner on scene. Using the Utstein guidelines, cardiac aetiology may be assumed after exclusion of other causes ${ }^{11} ; 440$ of 508 events $(86.6 \%)$ were assigned to a cardiac aetiology, of which 272 $(53.5 \%)$ were definitely confirmed by other clinical data such as case records showing past medical history, inpatient investigations confirming pre-existing cardiac disease, and necropsy reports. Overall 250 of 508 patients $(49.2 \%)$ presented with a malignant ventricular arrhythmia, 376 were witnessed arrests $(74.0 \%)$, and bystander CPR was given to 154 (30.3\%).

Details of prehospital time intervals and procedures performed are shown in table 2 . Paramedics used one or more of their extended skills in over $90 \%$ of instances; on scene times (vehicle stops to departure from scene) ${ }^{11}$ were significantly lengthened (median $31.0 v 17.5$ minutes), but transfer times were marginally faster. Defibrillation was not performed significantly more often by either type of crew; overall 298 of 502 patients $(59.4 \%)$ were defibrillated at least once (missing data $=6$ ). Of 502 patients with information recorded, 216 $(43.0 \%)$ had received intravenous drugs and $56(11.2 \%)$ drugs by the endotracheal route. Two patients transported by a technician crew received intravenous drugs from a general practitioner accompanying the patient, and one was also intubated.

Outcome data are shown in table 3. The likelihood of a return of spontaneous circulation by the time of arrival at the $A \& E$ department was more than doubled for patients attended by paramedic crews compared to those comprised only of technicians $(18.9 \%$ $v 7.6 \%$, relative risk $=2.48,95 \%$ confidence interval 1.34 to 4.60 ). Similarly the likelihood of leaving $\mathrm{A} \& \mathrm{E}$ alive (being successfully 
Table 3 Outcome of cardiorespiratory arrest in 508 patients according to ambulance crew status

\begin{tabular}{|c|c|c|c|c|}
\hline \multirow[b]{2}{*}{ Patient outcome, number (\%) } & \multicolumn{3}{|l|}{ Crew status } & \multirow[b]{2}{*}{ Pvalue* } \\
\hline & Paramedic $(n=285)$ & Technician $(n=144)$ & Dual response $(n=79)$ & \\
\hline \multicolumn{5}{|l|}{ On arrival at $A \& E$} \\
\hline Return of spontaneous circulation & $54(18.9)$ & $11(7.6)$ & $11(13.9)$ & \multirow{3}{*}{0.004} \\
\hline CPR continued & $108(37.9)$ & $54(37.5)$ & $29(36.7)$ & \\
\hline $\begin{array}{l}\text { Declared dead on arrival/brought in dead } \\
\text { Leaving A\&E }\end{array}$ & $123(43.2)$ & $79(54.9)$ & $39(49.4)$ & \\
\hline Alive & $57(20.0)$ & $15(10.4)$ & $14(17.7)$ & \multirow{2}{*}{0.002} \\
\hline Dead & $228(80.0)$ & $129(89.6)$ & $65(82.3)$ & \\
\hline \multicolumn{5}{|l|}{ Leaving hospital } \\
\hline Alive & $23(8.1)$ & $9(6.3)$ & $1(1.3)$ & \multirow{2}{*}{0.63} \\
\hline Dead & $262(91.9)$ & $135(93.8)$ & $78(98.7)$ & \\
\hline
\end{tabular}

* Paramedic versus technician (dual response excluded).

admitted to hospital) appeared to be doubled among patients initially treated by paramedics $(20.0 \% v 10.4 \%, \mathrm{RR}=1.92,95 \%$ CI 1.13 to 3.27). However, these differences in survival had largely disappeared by the time of hospital discharge; a trend was apparent towards improved outcome in patients attended by paramedics but this failed to reach statistical significance $(8.1 \%$ v $6.3 \%, \mathrm{RR}=1.29,95 \% \mathrm{CI}$ 0.61 to 2.72 ). These data are summarised in figure 1. Dual response calls appeared to produce short term outcomes similar to those of paramedic crews, but survival to hospital discharge was very much worse in this group compared to all others.

Four hundred and twenty nine incidents were potentially available for analysis by Poisson regression; however, because of the need for complete data across all variables, between 412 and 418 incidents could be entered into each of the three final models. In the third model it was not possible to enter a variable for witnessed arrest because no unwitnessed arrests successfully reached hospital discharge. When the variable for response times was further examined, it became apparent that its effect was best summarised by condensing into a dichotomous variable, above and below the median value; this modification was used in all three final models.

The results of the main regression analyses are shown in table 4; dual response incidents are excluded. The effect of each variable on survival is shown after adjustment for all of the others in each model. Examination of the first model, after adjustment for other significant factors, showed that the likelihood of arriving in the $A \& E$ department with a return of spontaneous circulation was more than doubled

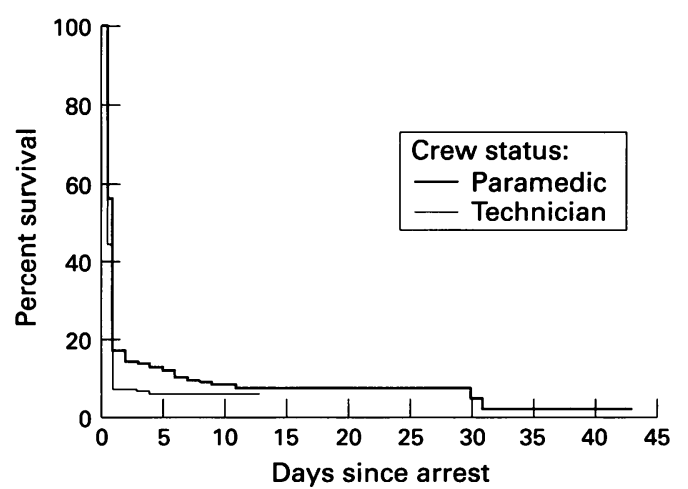

Figure 1 Survival after 429 out of hospital cardiac arrests according to ambulance crew status. among patients attended by paramedics $(R R=$ $2.24,95 \%$ CI 1.16 to 4.31 ). The second regression model showed that paramedic care did not significantly influence the likelihood of successful hospital admission $(R R=1.69,95 \%$ CI 0.91 to 3.14 ). The third regression model also showed that paramedic care did not significantly increase the likelihood of live discharge from hospital $(R R=1.21,95 \% \mathrm{CI}$ 0.50 to 2.91). Other factors identified as important determinants of enhanced survival included the presence of a medical practitioner at the scene of the arrest, witnessed arrests, initial ventricular arrhythmias, non-cardiac aetiologies, and short transfer times between the scene of the arrest and the $\mathrm{A} \& \mathrm{E}$ department. The alternative regression models, based on smaller numbers but including a term to adjust for the fact that some patients suffered their cardiac arrest after the ambulance crew had arrived, produced highly similar results. The likelihoods of both arriving live at $A \& E$ and leaving hospital alive were increased for patients who suffered their cardiac arrest after arrival of the ambulance crew $(R R=1.79,95 \%$ CI 1.03 to 3.09 ; and $3.85,95 \%$ CI 1.63 to 9.08 , respectively), but these did not alter the estimates for crew status or their previous statistical significance (data available on request).

In extending the first model (status on arrival at $A \& E)$ a significant interaction was detected between crew status and presenting rhythm (likelihood ratio statistic on $1 \mathrm{df}=$ $5.82, P=0.02$ ). When the presenting arrhythmia was of ventricular origin there was a trend towards increased likelihood of arriving at $\mathrm{A} \& \mathrm{E}$ with a return of spontaneous circulation after paramedic attendance, but this did not reach statistical significance $(R R=1.37,95 \%$ CI 0.66 to 2.81 ). However, the short term survival benefit gained by paramedic treatment was considerably greater among patients who presented with non-ventricular arrhythmias, and reached statistical significance $(R R=11.3$, $95 \% \mathrm{CI} 1.51$ to 84.3 ). When extending the second model (admission to hospital) no significant interactions were detected. Extending the third regression model (status on leaving hospital) revealed a significant interaction between crew status and underlying aetiology (likelihood ratio statistic on $1 \mathrm{df}=4.48, \mathrm{P}=$ $0.03)$. Among patients with underlying cardiac aetiologies there was a trend towards increased likelihood of survival to discharge $(R R=1.98$, 
Table 4 Factors associated with survival after out of hospital cardiac arrest: results of Poisson regression modelling

\begin{tabular}{|c|c|c|c|}
\hline Patient outcome (number in model) & Factor & Pvalue & Rate ratio $(95 \% C I)$ \\
\hline \multirow[t]{5}{*}{ Alive on arrival at $A \& E(n=412)$} & Paramedic crew & 0.016 & $2.24(1.16$ to 4.31$)$ \\
\hline & $\begin{array}{l}\text { Medical practitioner } \\
\text { present }\end{array}$ & 0.04 & $2.20(1.04$ to 4.66$)$ \\
\hline & Witnessed arrest & 0.007 & $5.02(1.56$ to 16.2$)$ \\
\hline & Initial ventricular rhythm & 0.026 & 1.88 (1.08 to 3.27$)$ \\
\hline & Cardiac aetiology & 0.011 & $0.44(0.24$ to 0.83$)$ \\
\hline \multirow[t]{6}{*}{ Alive leaving $A \& E(n=418)$} & Paramedic crew & 0.095 & $1.69(0.91$ to 3.14$)$ \\
\hline & $\begin{array}{l}\text { Medical practitioner } \\
\text { present }\end{array}$ & 0.027 & $2.24(1.10$ to 4.59$)$ \\
\hline & Witnessed arrest & 0.017 & $3.50(1.26$ to 9.75$)$ \\
\hline & Initial ventricular rhythm & 0.003 & 2.31 (1.32 to 4.03$)$ \\
\hline & Cardiac aetiology & 0.002 & $0.37(0.20$ to 0.69$)$ \\
\hline & Transfer time $>7 \mathrm{~min}$ & 0.048 & $0.60(0.36$ to 0.99$)$ \\
\hline \multirow[t]{5}{*}{ Alive leaving hospital $(n=418)$} & Paramedic crew & 0.666 & $1.21(0.50$ to 2.91$)$ \\
\hline & $\begin{array}{l}\text { Medical practitioner } \\
\text { present }\end{array}$ & 0.004 & 3.89 (1.55 to 9.79$)$ \\
\hline & Initial ventricular rhythm & $<0.001$ & 5.97 (2.11 to 16.9$)$ \\
\hline & Cardiac aetiology & 0.034 & $0.32(0.11$ to 0.92$)$ \\
\hline & Transfer time $>7 \mathrm{~min}$ & 0.01 & $0.32(0.13$ to 0.76$)$ \\
\hline
\end{tabular}

$95 \%$ CI 0.67 to 5.87 ) but this did not reach statistical significance. This trend was reversed among patients with non-cardiac aetiologies where those attended by paramedics seemed less likely to survive to hospital discharge (RR $=0.21,95 \%$ CI 0.03 to 1.31 ), although this again did not reach statistical significance.

Of 57 patients treated initially by paramedics and successfully admitted to hospital, 34 $(59.6 \%)$ did not survive to hospital discharge; in comparison, six of 15 patients attended by technicians $(40.0 \%)$ and 13 of 14 treated by dual response $(92.9 \%)$ died after admission $\left(\chi^{2}\right.$ $=8.84$ with $2 \mathrm{df}, P=0.012)$. GlasgowPittsburgh ratings for cerebral and overall function are shown in table 5 for patients who survived to hospital admission but did not survive to discharge. For the vast majority of these patients, the best level of functioning recorded postarrest was extremely poor, indicating high levels of disability/dependency at all times between hospital admission and death. In contrast, of the 33 patients successfully discharged from hospital, 31 (93.9\%) were noted to be healthy, alert, and capable of leading normal lives; the remaining two patients $(6.1 \%)$ were independent in the activities of daily living but disabled for competitive work.

For patients admitted and successfully discharged from hospital, length of stay did not vary significantly according to crew status (paramedic $v$ technician: median $8.0 v 9.0$ days, Mann-Whitney test: $\mathrm{z}=-0.68, \mathrm{P}=$ $0.50)$. However, for those patients who were admitted and subsequently died, lengths of stay were significantly greater if the patient was treated initially by a paramedic crew (median $3.5 v 1.0$ days, Mann-Whitney test: $\mathrm{z}=-1.97$, $P=0.05)$.

\section{Discussion}

In Britain there has been a phased introduction of paramedic ambulance staff between 1987 and the government-set deadline which expired in January 1996. All emergency ambulances should now contain at least one paramedic trained crew member; the time period under investigation in this study there- fore represented a unique opportunity which is unlikely to be repeated outside the context of a randomised controlled trial. To our knowledge, this is the first British study to have considered the effectiveness of paramedic ambulance staff using multivariate analyses to adjust for other prognostic factors which might act as confounding variables, and also avoiding the problems of multiple subgroup analyses. In Nottinghamshire all emergency ambulance personnel can perform defibrillation; therefore the comparisons in this study test the effect of paramedic extended training. Emergency calls are assigned by selecting the nearest available vehicle, regardless of crew status; thus no conscious bias should have been introduced in the assignment of patients to either type of ambulance crew. As with all retrospective studies it is impossible to guarantee that all eligible patients were identified, however, all reasonable steps were taken to ensure complete ascertainment. Perhaps one inevitable criticism of this study is the extent of missing data $(30 \%)$, despite exhaustive efforts to trace missing records; we accept that this a potential source of bias. While the data on the initial cardiac arrhythmia were not independently verified, previous work has shown that the use of semiautomatic external defibrillators (such as the ones used in Nottingham) by ambulance personnel produces a sensitivity and specificity of $82.4 \%$ and $99.7 \%$ respectively for the recognition of malignant ventricular arrhythmias. ${ }^{16}$

The overall survival rate to hospital discharge after cardiac arrest was $6.5 \%$; this value is remarkably similar to those described by other contemporary British data, ${ }^{17-19}$ suggesting that our findings may be applicable to other areas of the United Kingdom. In the univariate analysis, the chances of a return of spontaneous circulation and hospital admission were both significantly increased for patients treated by paramedics. We did not detect any significant difference at the point of hospital discharge. The data strongly suggest that the initial survival advantage associated with paramedic care diminishes rapidly over time. A small retrospective study in Hampshire has produced similar results: the proportion of patients who regained spontaneous circulation after paramedic care increased significantly by $75 \%$, but the proportion surviving to hospital discharge did not increase in parallel. ${ }^{10}$

Important comparative data have also been produced by Shuster et al from Ontario, Canada. These researchers compared the effectiveness of paramedics versus technicians trained in defibrillation for the management of acute cardiac illness. ${ }^{20}$ By using multiple regression, they concluded that in an urban setting, where transport times were on average less than 10 minutes, the availability of prehospital paramedic care was unimportant. ${ }^{20}$ Guly et al failed to show any difference in effectiveness between paramedic and technician crews for the management of out of hospital cardiac arrests. ${ }^{9}$ A closer examination of these data suggests that paramedics were possibly less effective than technicians (survival to discharge: $5.4 \% v 9.5 \%, \mathrm{P}=0.087)^{9}$; in contrast 
Table 5 Best cerebral perfomance score and overall performance score for 53 patients successfully admitted to hospital after cardiac arrest, who died before discharge

\begin{tabular}{|c|c|c|c|}
\hline \multirow[b]{2}{*}{ Performance score, number (\%) } & \multicolumn{3}{|l|}{ Crew status } \\
\hline & Paramedic $(n=34)$ & Technician $(n=6)$ & $\begin{array}{l}\text { Dual response } \\
(n=13)\end{array}$ \\
\hline \multicolumn{4}{|l|}{ Cerebral } \\
\hline 1 Alert, able to work and lead a normal life & $0(0.0)$ & $0(0.0)$ & $0(0.0)$ \\
\hline $\begin{array}{l}2 \text { Able to work part-time in sheltered environment, independent in } \\
\text { activities of daily life }\end{array}$ & $2(5.9)$ & $0(0.0)$ & $1(7.7)$ \\
\hline 3 Dependent on others for daily support. Limited cognition. & & & \\
\hline Usually institutionalised & $4(11.8)$ & $0(0.0)$ & $1(7.7)$ \\
\hline Coma, vegetative state & $28(82.4)$ & $6(100.0)$ & $11(84.6)$ \\
\hline 5 Certified brain death & $0(0.0)$ & $0(0.0)$ & $0(0.0)$ \\
\hline \multicolumn{4}{|l|}{ Overall } \\
\hline 1 Healthy, alert, capable of normal life & $0(0.0)$ & $0(0.0)$ & $0(0.0)$ \\
\hline 2 Performs independent activities of daily living. Disabled for & & & \\
\hline 3 Competitative work & $\begin{array}{l}1(2.9) \\
5(14.7)\end{array}$ & $\begin{array}{l}0(0.0) \\
0(0.0)\end{array}$ & $\begin{array}{l}1(7.7) \\
1(7.7)\end{array}$ \\
\hline 4 Coma, vegetative state & $28(82.4)$ & $6(100.0)$ & $11(84.6)$ \\
\hline 5 Certified brain dead & $0(0.0)$ & $0(0.0)$ & $0(0.0)$ \\
\hline
\end{tabular}

our study showed a small benefit in favour of paramedic crews which was similarly nonsignificant $(8.1 \% v 6.3 \%, P=0.63)$. Several explanations for this difference are possible. In Edinburgh, paramedic crews were not permitted to give cardiac drugs, ${ }^{9}$ and rapid response paramedic units were in operation alongside standard emergency ambulances. ${ }^{21}$ In Edinburgh, dual response calls were analysed within the paramedic group'; we excluded these because it was felt that although a paramedic had attended, an extra delay had occurred resulting from a technician based decision. Our data subsequently suggested these incidents are associated with a particularly dismal prognosis, justifying their handling as a separate group, and partially explaining the differences between the Nottingham and Edinburgh data. Only cardiac aetiologies were considered in Edinburgh, whereas the present study sought a broader pragmatic view by including all aetiologies, although this heterogeneity was adjusted for in the analysis. Guly et al included only patients whose treatment was continued in the A\&E department,' whereas our study deliberately considered patients declared dead on arrival. Other studies show that paramedic crews are more likely than their technician colleagues to begin resuscitation ${ }^{22}$; therefore this may have been an important source of selection bias. ${ }^{23}$ Balancing the inclusion of 241 such patients against the non-availability of a further 215 case records ( $>95 \%$ of all missing data) partial success was achieved in reducing this potential flaw.

The main regression models confirmed our initial findings. In addition, witnessed arrest, initial ventricular arrhythmia, shorter transfer times, and the presence of a medical practitioner on scene were identified as factors significantly associated with improved outcome. Many of these have been described as important prognostic indicators in previous studies, ${ }^{24-26}$ supporting the validity of our study design. Bystander CPR has also been identified by previous studies as an important prognostic factor ${ }^{72}$; we failed to confirm this, probably because bystander CPR is known to be related to witnessed arrests and shorter access times to definitive care, ${ }^{28}$ and these factors were included in each regression model.
The presence of a doctor at the scene of the arrest was strongly associated with improved survival to hospital discharge. This result is almost certainly due to selection bias. General practitioners are less likely than ambulance crews to be called to patients who suddenly collapse; furthermore GPs confronted by a cardiac arrest during the course of a domiciliary visit will be most likely to call an emergency ambulance and begin resuscitating the patient when they believe the chances and benefits of survival would be worthwhile. Thus among patients where the GP was already in attendance at the time of the arrest, possibly only those with the best prognoses are included in this study.

Second level modelling using product terms revealed several interesting trends. In the first model (status on arrival at $A \& E$ ) paramedics were not significantly better than technicians in managing ventricular arrhythmias. This trend is consistent with the fact that defibrillatory shock (by far the most effective treatment for ventricular fibrillation) is performed by both types of crew. In contrast, cardiac drugs (given only by paramedics) may be the only potentially useful treatment for the prehospital management of non-ventricular arrhythmias; this may explain why paramedics produced significantly improved short term survival compared with technicians in these circumstances. In the third model (status on leaving hospital) there was a trend towards increased survival among patients with cardiac aetiologies who were managed by paramedics, whereas this finding was reversed for patients with non-cardiac aetiologies (predominantly trauma). This finding was unexpected; however, it may reflect the controversy about whether it is better to "stay and stabilise" trauma patients (as exemplified by paramedic care) or to "scoop and run" (the only option for technician crews).

This paper provides new information on the effectiveness of paramedic versus technician ambulance staff for the management of out of hospital cardiac arrest. The available data suggest that the use of paramedic training and skills has a major impact on intermediate outcomes such as return of spontaneous circulation on or before arrival in the A\&E department (especially for non-ventricular arrhythmias), and successful 
hospital admission. Our study lacked sufficient statistical power to fully consider longer term outcomes; these are the focus of another ongoing study in Nottingham. However, the size of any survival benefit appears to decline rapidly over time and may be confined to patients with cardiac aetiologies.

In reaching our conclusions, we have examined only one of the many roles played by paramedics within a modern emergency medical system; in Nottingham, cardiac arrests constitute only $4-5 \%$ of all emergency ambulance calls (Nottinghamshire Ambulance Service NHS Trust, unpublished observations, 1996). Further large studies are required to confirm or refute our findings, and evaluate the role of paramedics in other emergency situations such as severe trauma, and respiratory and metabolic emergencies. Only then will it be safe to fully justify or challenge this programme of patient care.

We wish to thank $\mathrm{Mr}$ Mike Handy, Chief Executive Nottinghamshire Ambulance Service NHS Trust. Financia support was provided by Nottingham Health Authority.

1 Department of Health and Social Security. NHS ambulance services: extended training for ambulance staff. London: DHSS, 1984 [circular DA(84)12].

2 Merifield AJ. The modern ambulance service. Report by Working Group to NHS Management Executive, 1990.

3 Weaver WD, Hill D, Fahrenbruch CE, Copass MK, Martin

JS, Cobb LA, et al. Use of the automatic external defibrillaJS, Cobb LA, et al. Use of the automatic external defibrilla-
tor in the management of out-of-hospital cardiac arrest. N tor in the management of out-of

4 Stults KR, Brown DD, Schug VL, Bean JA. Prehospital defibrillation performed by emergency medical technician in rural communities. N Engl J Med 1984;310:219-23.

5 Watts DD. Defibrillation by basic emergency medica technicians: effect on survival. Ann Emerg Med 1995;26. 635-9.

6 Auble TE, Menegazzi JJ, Paris PM. Effect of out-of-hospita defibrillation by basic life support providers on cardia arrest mortality: a meta-analysis. Ann Emerg Med 1995;25:642-8.

7 Hoekstra J. Bystander CPR: a review. Resuscitation 1990;20:97-113.

8 National Health Service Training Directorate. National Health Service training manual. Bristol: NHSTD, Swindon Press, 1991.

9 Guly UM, Mitchell RG, Cook R, Steedman DJ, Robertson CE. Paramedics and technicians are equally successful at managing cardiac arrest outside hospital. BMJ 1995;310 $1091-4$.

10 Mann CJ, Heyworth JRC. Management of cardiac arrest by ambulance technicians and paramedics: benefit of paramedics in non-ventricular fibrillation arrests is transitory. BMJ 1995;311:508-9.
11 Chamberlain D, Cummins RO, Abramson N, Allen M, Basket $\mathrm{P}$, Becker L, et al. Recommended guidelines for uniform reporting of data from out-of-hospital cardiac arrest (new abridged version). Br Heart J 1992;67:325-33.

12 Eisenberg MS, Bergner L, Hearne T Out-of-hospital cardiac arrest: a review of major studies and a proposed cardiac arrest: a review of major studies and a proposed uniform

13 Jennett B, Bond $M$. Assessment of outcome after severe brain damage: a practical scale. Lancet $1975 ; \mathrm{i}: 480-4$

14 Brain Resuscitation Clinical Trial I Study Group. Randomised clinical study of cardiopulmonary-cerebral resuscitation: design, methods, and patient characteristics. Am J Emerg Med 1986;4:72-86.

15 The Royal College of Physicians of London. Independent ethical review of studies involving personal medical records. Report of a Working Group to the Royal College of records. Report of a Working Group to the Royal College of Physicians Committee on Ethical Issues

16 Sedgwick ML, Watson J, Dalziel K, Carrington DJ, Cobbe SM. Efficacy of out of hospital defibrillation by ambulance technicians using automated external defibrillators. The Heartstart Scotland Project. Resuscitation 1992;24:73-87.

17 Wright D, Bannister J, Ryder M, Mackintosh AF. Resuscitation of patients with cardiac arrest by ambulance staff with extended training in West Yorkshire. BMJ 1990;301:600-2.

18 Cobbe SM, Redmond MJ, Watson JM, Hollingworth J, Carrington DJ. "Heartstart Scotland" - initial experience of a national scheme for out of hospital defibrillation. BMJ 1991;302:1517-20.

19 Weston CFM, Stephens MR. An audit of cardiac arrest management by extended trained ambulance crew. Resuscitation 1992;23:207-16.

20 Shuster M, Keller J, Shannon H. Effects of prehospital care on outcome in patients with cardiac illness. Ann Emerg Med 1995;26:138-45.

21 Marsden AK, Cobbe SM. Management of cardiac arrest by ambulance technicians and paramedics: paramedics have other uses beside attending cardiac arrests. BMJ 1995;311: 508 .

22 Weston CFM, Burrell CC, Jones SD. Failure of ambulance crew to initiate cardiopulmonary resuscitation. Resuscitation 1995;29:41-6.

23 Weston CFM, Donnelly P. Management of cardiac arrest by ambulance technicians and paramedics: Studying only admissions is a source of potential bias. BMJ 1995;311: 509.

24 Sedgwick ML, Dalziel K, Watson J, Carrington DJ, Cobbe SM. Performance of an established system of first responder out-of-hospital defibrillation. The results of the responder out-of-hospital defibrillation. The results of the "Utstein Style". Resuscitation 1993;26:75-88.

25 Spaite DW, Hanlon T, Criss EA, Valenzuela TD, Wright AL, Kealey KT, et al. Prehospital cardiac arrest: the impact of witnessed collapse and bystander CPR in a metropolitan EMS system with short response times. Ann Emerg Med 1990;19:1264-9.

26 Roth R, Steward RD, Rogers K, Cannon GM. Out-ofhospital cardiac arrest: factors associated with survival. Ann Emerg Med 1984;13:237-43.

27 Grubb NR, Elton RA, Fox KAA. In-hospital mortality after out-of-hospital cardiac arrest. Lancet 1995;346:417-21.

28 Bossaert L, Van Hoeyweghen R, The Cerebral Resuscitation Study Group. Bystander cardiopulmonary resuscitation (CPR) in out-of-hospital cardiac arrest. Resuscitation 1989;17:S55-69. 